Uroš Dojčinović

ALUM

Akademija lepih umetnosti i medija

Beograd
УДК 004.738.5:78

доИ https://doi.org/10.18485/

melissa.2016.15.1.ch4

\title{
VIRTUELNA MUZIČKA NASTAVA I DIGITALNI IZVORI MUZIKALIJA
}

\section{Sažetak}

Muzička umetnost je, paralelno drugim humanističkim disciplinama, od početka pratila tehnološki razvoj. Pojavom interneta su na globalnom nivou učinjeni praktično svi teoretski i praktični muzički aspekti pristupačnim i otvorenim za različite vidove interakcija. Pojedini programi poput skajpa (skype), posebno pogoduju realizaciji muzičke nastave, te je danas takozvano "učenje na daljini“ sve prisutnije i u domaćoj muzičkoj praksi. Rezultati i kvalitativne karakteristike takve, istovremeno audio-vizuelene kominikacije, kakvu omogućava virtuelna edukacija, mogu se posebno razmotriti u domenu instrumentalne muzike. Sličan učinak interneta ostvaren je i formiranjem izuzetnog kvantuma digitalne produkcije muzičke literature. Međutim, i tu treba ukazati na pozitivne ali i negativne efekte tako obimnog i često ne-selektivnog opusa muzikalija, koji je danas učinjen lako dostupnim.

Ključne reči: Muzika, pedagogija, internet, skajp (skype), muzikalije

\section{Virtuelna muzička nastava i digitalni izvori muzikalija}

Muzička umetnost, kao i druge humanističke nauke, kontinuirano prati ljudski razvoj i napredak, pa tako i tehnološki. Pojava elektronskog medija - interneta i primena digitalnih tehnologija, poseban učinak su pokazali u određenim muzičkim sferama, među kojima izdvajamo pedagogiju. Virtuelna nastava, danas lako omogućena upotrebom računara i internet mreže, uz brzu i laku dostupnost brojnim i raznovrsnim elektronskim izvorima muzikalija, praktično su na globalnom nivou otvorile neograničene mogućnosti, kako za teoretsko-stručno upućivanje i proučavanje, tako i široko lično muzičko obučavanje i prezentaciju sopst- 
venog umeća muziciranja. Imajući u vidu da je profesionalno autoru ovog referata naročito bliska problematika klasične gitare (i srodnih trzalačkih kordofona), nadalje će biti reči o razvoju virtuelne nastave vezane upravo za sviranje ovih instrumenata. ${ }^{1}$

Onog trenutka kada se u muzičkoj praksi pojavio trajni nosač zvuka (najpre voštani cilindar, potom gramofonska ploča i muzička kaseta, kasnije CD i DVD album itd.), javila se i potreba za snimanjem didaktičkoinstruktivne notne literature. Muzički primeri komponovani u formi tehničkih vežbi, studija i etida, počeli su da se pojavljuju sa ostalim beleženim izvođačkim i koncertnim repertoarom. $U$ početku su to bili pojedinačni, samostalni diskografski naslovi, ${ }^{2}$ da bi se onda konkretne audio didaktičke ilustracije, sve češće priređivale i distribuirale, kao sastavni deo određenih instruktivnih muzikalija. Usledila je zatim prava bujica albuma čiji su sadržaji neretko donosili i čitave opuse tehničkih studija i etida autora umetničke muzike (Fernanda Sora (1778-1839), Maura Giulianija (1781-1829), Heitor Villa-Lobosa (1887-1959) i dr.). Sa pojavom video kasete, a potom i DVD-albuma, raspon audio-vizulenih mogućnosti je znatno zaokružen i recipijentima je kroz sliku i ton, a neretko i uz zvuk instrumenta i verbalnu eksplikaciju samog izvođača, omogućeno sveobuhvatnije upoznavanje sa meterijom. Tada su ton i slika na platunu ili ekranu, bez onih ograničenja kakve postavljaju prostor i vreme, a po najviše ekonomski momenti, pokušavali da nadomeste ili dopune živu, organizovanu, nastavu i prisustvo nastavnika. ${ }^{3}$

1 Podsećamo da obilje različitih elektronskih instruktivnih priloga obuhvata i druge aspekte muzičke problematike, pa tako $u$ domenu instrumentalne muzike i izradu i reparaciju muzičkih instrumentata.

2 Među prvim projektima ove vrste izdvajaju se LP-albumi realizovani u periodu od 19621972: Andres Segovia / Vežbe za razvijanje tehnike (uveo i objasnio autor), LP MCA 2535 (tj. DECCA DL 710179); Andres Segovia / Tehničke formule, LP MCA 2536 (tj. DECCA DL 710182). Slavni španski gitarista Segovia (1893-1987) po prvi put snima svoje izvođenje muzičkih lestvica, arpeđa (arpeggio) i kratkih etida sa elementarnim tehničkim zahtevima. Takve prvence predstavljaju filmovane majstorske klase klasične gitare, koje je 1965. godine održao već pomenuti Andres Segovia, u Santiagu de Compostelli u Španiji. Serija snimljenih video kaseta (kasnije revidiran materijal prebačen na DVD albume), zebeležile su njegovo izvođenje žive nastave. Videti: The Library of Master Performes : Seagovia Master Class Series. - National Educational Television and Radio Center, 1966. Različite izdavačke kuće počinju zatim da plasiraju na tržište posebno osmišljene i snimljene instruktivne sadržaje, u kojima pojedini izvođači i pedagozi demonstriraju tehnike sviranja, 
Međutim, u okruženju koje se brzo i konstantno menjalo, i u kojem su potrebe za zadovoljenje sve masovnijeg broja interesenata neprestano rasle, dotadašnji navedeni audio i audio-vizuelni izvori i dalje su bili nedovoljni i ograničenog karaktera. Materijalna situacija, geografske granice i sve druge slične barijere, često su sprečavale potrebni protok ovih izdanja, pa su veliki delovi populacije bili uskraćeni čak i za elementarno saznanje o postojanju takvih muzičkih naslova.

Na sreću, pojava i upotreba računara i njegova dostignuta popularnost na globalnom nivou, može se reći da su iz korena sve izmenili, pa tako i stanje u oblasti muzike. Pristup digitalizovanim muzičkim sadržajima, koje danas svakom pojedincu omogućava kompjuter, postali su nova paradigma savremenog bavljenja ovom umetnošću. Svi virtuelni muzički sadržaji, najpre oni dostupni u ograničenom obimu (prvobitno na CD ili DVD-ROMu), a potom preko interneta otvoreni i za različite oblike potencijalne interakcije i modifikacije, iako u fizičkom smislu realno odsutni, sada su virtuelno učinjeni svima dostupnim i funkcionalnim. Jasno je da su sa razvojem ove moderne tehnologije, koja je omogućila kompjutersko kreiranje posebne stvarnosti, obuhvaćeni i svi teoretski i praktični aspekti muzičke problematike.

Prvi vidovi virtuelne instrumentalne nastave, različita upućivanja i poučavanja u izvođenju, najpre su se svodili na digitalizaciju postojećeg klasično štampanog ili umnožavanog materijala.Veliki broj izdavačkih kuća, čija je dotadašnja tradicionalna distribucija i prodaja instruktivnodidaktičkih izdanja ipak bila ograničena, novom virtuelnom tržištu počeo je da nudi i njihove elektronske verzije. Od tog momenta, korisnicima računara povezanog u svetski komunikacioni sistem umreženih računarskih mreža - Intenet, bilo kada i bilo gde da su se nalazili, svi takvi vizuelni, auditivni i audiovizuelni sadržaji postajali su dostupni. Nji-

objašnjavaju posebne muzičke žanrove, elaboriraju određene kompozitore i njihova dela i sl. Navešćemo video-kasetu: Paco Serrano, La guitarra flamenca. - Meilen : Encuentro productions, 1993. Određen broj muzičkih kompanija, kakva je američka MelBay publikacije, izdvojio se izuzetno brojnom edicijom ovako profilisanih naslova. Pomenimo DVD albume: Charles Postlewate, Five-Finger Technique. Pacific, MO : Mel Bay Publications, Inc. (MB20962), 2004; i Stanley Yats and Graham Wade, Francisco Tarrega : His Life and Music. Pacific, MO : Mel Bay Publications, Inc. (MB21754), 2008. Posebno izanje vredno pažnje je: Jorge Cardoso, Tecnica de la guitarra clasica (DVD). Madrid : RGB Arte Visual,2007. 
hova kvalitativna selekcija u početku je diktirana samom činjenicom da su posredstvom novih tehnologija i medija prvo prezentovani relativno malobrojni izdavački projekti, proverenih autora. Stručne instrukcije date od strane renomiranih umetnika i pedagoga, kakav je bio npr. pomenuti Andres Segovia, bez svake sumnje mogle su se smatrati pouzdanim.

Ipak, početni period kratko je trajao, da bi procvat elektronskog tržišta uslovio neverovatan kvantitet ovakvih digitalnih sadržaja, čiji porast i dalje nezaustavljivo raste. Pojava američkog „Ju-tjub“ sajta (YouTube) iz 2005. godine, koji korisnicima pruža posebne oblike video-razmena i tehnički otvara veliki spektar mogućnosti za prikazivanje, uz medijske korporacije i druge organizacije, i pojedincima je dozvolio objavljivanje najrazličitijih sadržaja. Podsećamo da je ogromna većina njih potpuno slobodna za gledanje. ${ }^{4}$ Danas, takvi dostupni prilozi, uz filmske i televizijske snimke, muzičke spotove, audio numere i druge video snimke različite dužine i sadržaja, uključuju i edukativni materijal. Koliki je broj postojećih priloga, povezanih sa učenjem gitare, nemoguće je precizno utvrditi, ali kao ilustracija može poslužiti informacija da pretraživanjem na Guglu (Google) ${ }^{5}$ jednim upitom: "Koliko škola za gitaru postoji na Ju-tjubu ", za samo 0.83 sekunde, prikazan je rezultat od oko 12.100 .000 ponuđenih linkova. Na nešto preciznije pitanje: "Koliko škola za klasičnu gitaru postoji na Ju-tjubu", skoro istovremeno (za 0.84 sekunde), ponuđeno je oko 3.560.000 linkova.

Informacionu i komunikacionu razrađenost ovakvih programa ponajbolje potvrđuju posebni sajtovi, koji reklamiraju virtuelni svet gitare; jedan od njih izdvaja "50 vrhunskih Ju-tjub gitarskih kanala", koji uz časove instrumenta, pružaju i informacije o: gitaristima izvođačima, zatim proizvođačima gitara, gitarskoj periodici, prodavnicama gitara, ali i skoro svemu drugom, orijentisanom na ovaj instrument. ${ }^{6}$ Interesantna je

4 Dok neregistrovani korisnici imaju samo mogućnost gledanja i slušanja video priloga na YouTube, registrovanima je omogućeno i njihovo neograničeno pravljenje i postavljanje, otpremanje (upload), dodavanje svojih komentara na video i sl.

5 Američka multinacionalna korporacija Google, specijalizovana za internetske proizvode i servise, omogućava između ostalog i pretragu na internetu.

6 Videti: Top 50 Youtube Guitar Channels - Guitar Treats: guitartreats.com/top-50youtube-guitar-channels

"The Top 50 Youtube Guitar Channels covers lessons, magazines, manufacturers, guitar stores, reviews, guitarists, and pretty much everything guitar centric." 
činjenica da je autor navedenog sajta, samo nakon dva meseca od njegovog postavljanja, još 2007. godine, konstatovao izuzetno veliki broj posetilaca; bez ikakve sumnje među njima je bilo mnogo onih, koji sebi nisu mogli da priušte drugačije časove, niti klasično organizovanu nastavu instrumenta. ${ }^{7}$

Postavlja se pitanje kako i na osnovu čega zainteresovana osoba može da odluči kojem virtuelnom instruktivnom programu da pristupi, a i kojem da se prepusti, ukoliko stvarno želi nešto temeljno da nauči? Bez elementarnog poznavanja instrumenta ili bilo kakvih stručnih preporuka, odluka može biti zaista teška. ${ }^{8}$ Hiljade formiranih linkova ističu izuzetno primamljive ponude, koje uglavnom, sa samo nekoliko reči, nastoje da privuku pažnju konzumenata. Oslonjeni na digitalne koncepte i modele savremenog marketinga, pravi su izazov za neupućene. Apostrofiraju brzo i sveobuhvatno zaokruživanje materije, garantuju uspeh, a često se ne libe da negiraju kvalitet drugh sličnih "škola", kao i sistema klasičnog obrazovanja. U prvi plan najčešće postavljaju primamljive pozive poput: "Naučite da svirate gitaru besplatno"(Learn to play the guitar for Free)

7 Izdvojeni su iz popisa kanali jasno namenjeni podučavanju sviranja na gitari, sa brojevima njihovih posetilaca koje navode autori sajta:

NextLevelGuitar.com (rockongoodpeople) 99,932,874 views - guitar lessons JustinGuitar.com \#2 (justinsandercoe) 51,719,520 views - guitar techniques GuitarJamz.com \#2 (guitarjamzdotcom) 46,967,937 views - guitar lessons True Fire (truefiretv) 29,295,874 views - guitar lessons

GuitarVideos.com (Free Guitar Videos) 29,098,589 views - guitar lessons Dolphinstreet (rotren) 26,104,512 views - lessons

Your Guitar Sage (yourguitarsage) 23,922,120 views - lessons

Berklee Music (berkleemusic) 16,479,784 views - lessons

GuitarJamz.com \#3 (youcanlearnguitar) 15,766,527 views - lessons and reviews John Heussenstam (johnhguitar) 9,258,731 views - reviews \& lessons

Stevie Snacks (gr8bluesgtr) 9,246,090 views - blues guitar lessons

GuitarJamz.com \#4 (martyfs74) 7,229,441 views - guitar tab lessons

Shred Academy (shredacademy) 4,904,549 views - heavy metal lessons

GuitarLessons.com (guitarlessonscom) 4,015,813 views - lessons

Guitar Lessons 365 (guitarlessons365) 3,540,785 views - lessons

Guitar Tricks (guitartricks) 2,809,461 views - guitar lessons

Jim Bruce (acoustictravellersl) 2,407,588 views - blues lessons

Diskutabilno može da bude čak i oslanjanje na klasifikacije i izdvajanja koja se mogu naći na internetu poput: Which YouTube channels are the best for beginners to learn to play ... https://www.quora.com ili Songvice- Top 5 YouTube Channels for beginner guitar lessons https://www.blog.songvice.com 
ili "Besplatni časovi gitare" (Free Guitar Lessons). Potom, te takozvane lične "On-lajn" (Online) radionice, kod kojih su časovi, školarina i tutorial besplatni, ubeđuju u prednost učenja instrumenta bez fizičkog prisustva nastavnika, ${ }^{9}$ naglašavajući da su upravo one ta mesta, na kojima se može naučiti čak i ono što inače ne bi učenici čuli od nastavnika: "Ovde je ono što ti tvoj učitelj gitare neće reći" (Here's What Your Guitar Teacher Won't Tell You); ${ }^{10}$ ili da za razliku od "nekolicine nastavnika koji mogu da predaju studentima iznad srednjeg nivoa", one omogućavaju potpuno usavršavanje, ${ }^{11}$ do toga da su prava zamena za veliki broj učitelja gitare, koji će samo potrošiti vreme učenika, tako što ne znaju kako da mu pomognu... ${ }^{12}$

Ovakne virtuelne lekcije namenjene su od onih koji su apsolutni početnici, do instrukcija za starije uzraste. ${ }^{13}$ Ponekad srećemo i metodično organizovanu nastavu, a u toku "korak po korak" časova, dotiču se različiti aspekti učenja gitare, razmatraju se različiti muzički žanrovi i naravno različiti varijeteti ovog instrumenta. ${ }^{14}$ Nažalost, konstantno je prisutna jedna ista dilema: može li virtuelna nastava instrumenta, kakvu omogućavju posete sajtovima na Ju-tjub kanalu, da zameni prave, "žive" časove instrumenta sa nastavnikom? Dosadašnja praksa potvrđuje da su upravo mnoga početna i površna internet upoznavanja sa gitarom, kod onih interesenata, koji su želeli da njome valjano ovladaju, završavala iznalaženjem pravog, "živog" učitelja. On-lajn učenje nikako ne pokazuje prednost nad pohađanjem klasičnih časova gitare. Ispostavlja se nedovoljnim, jer učenici neretko koriste pogrešnu instruktivnu literaturu, gube više vremena i često učvršćuju pogrešnu tehniku, stičući loše izvođačke navike, kojih se potom godinama ne mogu da oslobode. ${ }^{15}$

$9 \quad$ Naravno postoje i sajtovi koji koriste primereniju reklamu: „... Studiranje sa kvalifikovanim nastavnikom gitare je najbolji način da naučite, međutim online video su veliki resursi..." Videti: Stowmarket Guitar Lessons www.guitarlessonsstowmarket.com

10 Videti: Taking Guitar Lessons? https://www.ultimate-guitar.com

11 Videti: Cyberfret.com: Tom's YouTube Intro to Masters of Guitar www.cyberfret.com

12 Videti: How to Play Guitar for Beginners - \#1 Guitar Lesson on YouTube https://csgacademy. com/how-to-play-guitar-for-beginners

13 Pogledati kao primer: Guitar Lessons in Etobicoke: YouTube-Lessons; Beginner Guitar Lessons; Intermediate Guitar Lessons... Thereare many 100's of free video guitar lessons in all levels of rock, blues, metal ... www.etobicokeguitarschool.com

14 Videti: Free Lessons / Guitar Lessons 365 https://guitarlessons365.com/free-lessons

15 Globalni razvoj brzih elektronskih resursa, kojima korisnici mogu najčešće besplatno da pristupe, pomoću tehnički relativno jendostavnih elektronskih alata, možda jeste pridoneo 
Šta i kako uvežbavati, kako postići solidnu tehniku i dovesti je do maksimalnog savršenstva, jednom rečju kako dosegnuti ispravnu bazu koja omogućava kvalitetnu interpretaciju, u ovom slučaju je apsolutno subjektivno pitanje i varira u zavisnosti od svake individue pojedinačno. Prisustvo i uloga iskusnog nastavnika, koji stručno organizuje i vodi nastavni proces, prilagođavajući se potrebama od časa do časa, konstantno imajući u vidu psihofizičke sposobnosti i mogućnosti učenika ponaosob, nezamenljiv je činilac. Naravno, tek u skladu sa takvom ispravnom individualnom nastavom, dopunska upotreba svih ostalih adekvatnih On-lajn materijala može koristiti. Tim pre što elektronski mediji posredstvom menija omogućavaju da se u jednom istom programu, i u okviru jedne iste razmatrane teme, pristupi i velikom broju drugih informacijama najrazličitije prirode. Oni pružaju i mogućnost animacije, kao jednog od značajnih aduta novih računarskih tehnologija; dozvoljavaju fiktivno stvaranje virtuelnih slika i prikaza. To savremeni nastavni proces obogaćuje posebnom dimenzijom: moguće je virtualno analitički prikazati sve biomehaničke funkcije ljudskog tela prilikom sviranja, uključujući: postavku instrumenta, gestikulaciju tokom izvođenja, produkciju tona i sl. ${ }^{16}$ Ovakve virtuelno ilustracije drugačije bi bile neizvodljive.

Svakako ovde treba istaći i „Skajp“ (Skype) program, koji je brzo svoju primenu našao i u realizaciji muzičke nastave, popularno nazvanog "učenja na daljinu“. Ona je sve prisutnija i u domaćoj muzičkoj praksi. ${ }^{17}$ Besplatna komunikacija omogućena preko Skajpa kroz ton i sliku, korisnicima interneta, ma gde se oni nalazili, pruža daleko veće mogućnosti za

globalnoj revoiluciji u didaktici, omogućivši pristup sveukupnim resursima informacija, ali nikako nije potisnuo ulogu klasičnog nastavnika, koji izvodi "živi" individualan čas instrumentalne muzike sa učenikom.

16 Videti: Stefano Viola, Il Chitarrista : Biomeccanica, postura, gestualita, compensazioni. (DVD), Udine : Conservatorio statale di musica "Jacopo Tomadini“ ; Universita degli studi di Udine, 2012.

17 Mi ćemo izdvojiti beogradsku Školu gitare Božidara Đukića, http://skolagitarebozidardjukic. weebly.com. Reklamirajući časove klasične, džez, rok i gitare u narodnoj muzici putem Skupe-a, Božidar Đukić ističe da je njegov Program nastave, koji omogućava učenje instrumenta na daljinu, napravljen po programu muzičkih škola, kao i posebnom programu za sve vrste muzike, uključujući i balkanske (nepravilne i mešovote) ritmove. Autor navodi da notne zapise vežbi i melodija šalje učenicima putem interneta (elektronskom poštom i skype-om). Dodaje da se od 2008. godine putem Skype-a uspešno školuju učenici u Sjedinjenim Američkim Državama, Velikoj Britaniji, Australiji, Austriji, kao i u Srbiji. 
aktivniju kominikaciju i interakciju dve strane: nastavnik - učenik. U ovom slučaju učenik nije više samo pasivni posmatrač, data mu je prilika da uživo, direktno postavlja pitanja i da razgovora sa osobom koja ga podučava. Istovremeno, omogućeno je da demonstraciju onoga što je naučio nastavnik odmah komentariše i evaluira (njegovo izvođenje se može videti i čuti u trenutku kada se zaista i odigrava). ${ }^{18}$ Naravno, ono za šta je ovakav vid nastave uskraćen je i dalje mogićnost neposrednog fizičkog kontakta: nastavnik ne može lično, svojim dodirom da koriguje držanje instrumenta, postavku leve ili desne ruke, promeni ugao pristupa prsta struni i sl., kao što bi to mogao u okviru klasične nastave. Sve njegove instrukcije i dalje se svode samo na verbalna uputstva, bazirana na ličnom zapažanju dešavanja iz jednog određenog ugla, u zavisnosti od postavljenih kamera, a to svakako za specifičnu muzičku instrumentalnu nastavu nije dovoljno.

Dakle, imajući u vidu specifičnosti koje karakterišu proces muzičke nastave, upotreba računara sa svim njegovim mogućnostima i savremenim tehnilogijama, svakako da je i ovde našla svoju primenu, ali ona nikako ne može da isključi organizovan sistem tradicionalnog podučavanja u sviranju instrumenata. Šta više, možemo zaključiti da tek spoj klasičnog procesa nastave, sa virtuelnim elektronskim mogućnostima, u potpunosti zadovoljavaju savremene zahteve, i da su istovremeno prilagođeni potrebama našeg razvijenog informatičkog doba, ali i u skladu sa očuvanjem izvorne humanističko-prosvetiteljske tradicije.

Sličnu ulogu i funkciju ostvaruju i digitalni mediji, koji omogućavaju globalnu produkciju i promet muzičke literature. $U$ fokusu našeg razmatranja su pre svega stručne, notne muzikalije: instruktivno-didaktička literatura, koju čine različite Škole, Metode, Praktikumi i slične brošure i udžbenici za učenje sviranja na instrumentu, zatim kolekcije etida, studija i drugih tehničkih vežbi i najzad sva ostala notna izdanja. I u ovom slučaju brojne muzičko-izdavačke kuće danas nude čitave svoje opuse u elektronskoj formi. Jednostavni upiti

18 Osim ovih besplatnih video poziva preko Skajpa sagovornici mogu podeliti svoje ekrane (monitore) ili koristiti njihove delove, mogu slati različite datoteke (npr. muzičke poput: WAV, MIDI, MP3), posebne poruke itd. 
na Gugl: „,Koliko muzičke literature za gitaru postoji na internetu“ ili preciznije „koliko literature za klasičnu gitaru postoji na internetu“, u deliću sekunde rezultiraju hiljadama ponuda. Nemali deo te neverovatne produkcije, svakome je dostupan za besplatno preuzimanje (Download). Jasno je da tako obimna ponuda, koja nikako ne može biti potpuno selektivnog karaktera, jer joj se svakog trenutka, svaki pojedinac lako može priključiti i svojim radovima, sa sobom povlači i pozitivne, ali i negativne efekte.

S jedne strane srećemo se sa delatnošću različitih zvaničnih biblioteka, koje svoje bogate fondove nastoje da učine opštedostupnim, pa time svakako pravdaju socio-kulturni karatkter svojih usluga. ${ }^{19}$ Nažalost, njihovi elektronski katalozi još uvek sadrže jako ograničeno, ili nikako, naslove koje razmatra ovaj referat, a još manje poseduju stručne notne gitarske muzikalije raspoložive u elektronskoj formi ${ }^{20} \mathrm{~S}$ druge strane, profesionalnim poznavaocima materije poznate su i manje specijalizovane kuće, ali zbog svojih ograničenih kapaciteta, u reklamnom smislu, one nesrazmerno figurišu u medijima i time ostaju izvan vidokruga slabije upućenih interesenata i potencijalnih korisnika. ${ }^{21} \mathrm{Na}$ trećem mestu, nalaze se veliki renomirani izdavači muzikalija, koji sve češće pribegavaju prodaji svojih digitalizovanih naslova. Njihovi sadržaji uglavnom jesu provereni ali nisu besplatni, pa su široj javnosti manje i prihvatljivi. Kao i u slučaju virtuelene nastave, tako i po pitanju digitalne stručne literature, postoji praktično neograničen elektronski prostor za sve one koji samoinicijativno žele da plasiraju sopstvene muzikalije. Jasno je da se njihov kvalitet ne može apriori odbaciti, ali se uvek nameće realno pitanje njegovog postojanja?

19 Pomenimo da je i u Nardnoj biblioteci Srbije, još 2004. godine, oformljeno i počelo sa radom posebno Odeljenje za razvoj digitalne biblioteke i mikrografiju; započet je sveobuhvatni proces digitalizacije njihovog obimnog bibliotečkog fonda.

20 Kao izuzetak ističe se Kraljevska bibliotekla u Kopenhagenu (Royal Library in Copenhagen) u Danskoj, koja poseduje izuzetno bogatu kolekciju muzikalija, naročito stara izdanja i manuskripte.

21 Posebnu pažnju zavređuje Italijan Vincenzo Pocci sa svojom VP Music Media bibliotekom, fokusiranom na gitarističke projekte i specijalizovanom za distribuciju on-lajn muzičkih listova, knjiga i drugih baza podataka, sa suštinskim referencama o gitaristima, pedagozima, kompozitorima i bibliotekama. Pocci takođe upravlja i virtuelnom bibliotekom retkih i iz štampe povučenih izdanja. Njegov Katalog sadrži preko 50,000 naslova, među kojima su solističke i kamerne kompozicije za gitaru, nastale od 1900. godine, kao i izbor modernih dela savremenih autora. VP Music Media omogućava besplatno preuzimanje velikog broja svojih nalsova sa slobodnim pristupom obimnoj on-lajn bazi ABEMUSIC (Abel NagytothyToth) koja kompilara preko 30,000 kompozicija. http://www.vpmusicmedia.com 
Kako postupati pri izboru, na šta obraćati pažnju u dodiru sa lako pristupačnim muzikalijama, čime se rukovoditi u selekciji izabranog materijala za vežbanje i izvođenje? Samo su neka od pitanja, koja bi trebalo da se nametnu pre svega svakom početniku, ukoliko se odluči na virtuelno učenje sviranja, a pri tome se osloni i na lako dostupnu digitalnu literaturu. Zapažanja su da odsustvo tradicionalnih recenzenata ili kakvih kompetentnih poznavalaca materije, koji revidiraju takva izdanja, najčešće rezultira kompozicijama u kojima figurišu: pogrešan tekst (i ritmički, a neretko i visine određenih nota), neadekvatni prstoredi, uz obilje neispravnih ili diskutabilnih oznaka ta tempo, dinamiku, artikulaciju i sl. I u ovom slučaju, odsustvo pravih informacija i stručnih uputa, može da generiše obilje negativnih efekata, kasnije teško ispravljivih čak i pod kontrolom izuzetno kvalifikovanog nastavnika.

\section{Uroš Dojčinović}

\section{VIRTUAL TEACHING OF MUSIC AND DIGITAL MUSIC SOURCES}

\section{Summary}

Music, parallel to other humanities, from the beginning followed the technological development. With the appearance of the internet practically all theoretical and practical aspects of music were globally made accessible and open to various forms of interactions. Some programs, such as Skype, is particularly conducive to the realization of music teaching, and today the so-called "distance learning" is also more and more present in our domestic music practice. The results and the qualitative characteristics of such audio and visual communication, which allows the virtual education, can be particularly considered in the field of instrumental music. A similar effect achieved by internet is shown in the extremely large production of digital music literature. However, one must point out the positive, as well as negative effects of such a voluminous and often non-selective opus of music, which is today made easily accessible.

Key words: Music, pedagogy, internet, Skype, musical literature. 